\title{
Designing Information Literacy Instruction for the Life Sciences
}

\author{
Katherine O'Clair \\ California Polytechnic State University
}

\begin{abstract}
Information literacy for the life sciences differs from other disciplines and requires an approach that addresses the specific needs of the curriculum and its students. This chapter focuses on the important aspects to consider when designing information literacy for the life sciences, including characteristics of the curriculum and students, opportunities to collaborate with instructors to integrate information literacy, and strategies for developing assessment-based approaches. It provides recommended resources, specific guidance, and practical suggestions for librarians responsible for information literacy instruction in the life sciences disciplines.
\end{abstract}

Keywords: Information literacy, Instructional design, Assessment, Life Sciences, Students, Competencies, Learning objectives, Sciences

\section{Introduction}

This chapter addresses designing instruction for information literacy in the life sciences and is ideal for those seeking to learn more about planning and developing information literacy instruction for the life sciences disciplines. It is intended to be practical in nature, providing insight into the important things to consider when designing, delivering, and assessing student learning experiences. The focus is on undergraduate education as it applies to the widest audience, yet much of what is discussed can be applied to graduate students and graduate-level programs. This chapter will address the life sciences curriculum and characteristics of students in such programs and provide practice-based examples and approaches. Programmatic approaches for information literacy in the life sciences will be shared, and several tools and strategies used to design, deliver, and assess information literacy will be introduced. While there will always be subtle differences between the disciplines encompassed in the life 
sciences, this chapter will treat the life sciences in a general sense. The discipline-specific chapters that follow will provide further discussion of information literacy strategies for individual subjects within the life sciences.

\section{The Life Sciences Curriculum}

To be effective instructors, librarians should have an awareness of the disciplinary curriculum for which they are providing information literacy instruction. Again, the information presented here is general in nature, and librarians will want to familiarize themselves with the specific curricula at their institutions. Such knowledge helps to align the information literacy with the curriculum, thus enhancing the experience for students and contributing to their success in learning.

The science curriculum is inherently different from other curricula such as that for business or the humanities. Much of science deals with abstract concepts and theories (e.g., natural selection, conservation of energy) that cannot be directly observed (Leonard, 1997). The life sciences curriculum is broad and encompasses a wide range of disciplines including agriculture, marine science, polar science, and zoology. Courses in the life sciences majors typically contain a lecture component where the concepts and theories are taught. Some courses may have a complementary laboratory section in which student gain hands-on experience with the concepts they are learning in the lecture component. In addition, selected courses, especially those with which students commonly struggle, may contain a recitation section to provide additional time to address challenging or advanced concepts.

The requirements of the degree programs can vary from discipline to discipline and institution to institution, yet it is common for each to have specified program learning objectives that include knowledge of the discipline, as well as critical thinking and lifelong learning. Librarians should consult these learning objectives as they engage with faculty in the disciplines to design and plan information literacy activities. Additionally, some programs (e.g., human nutrition) may be accredited by outside organizations or governing bodies, and they may have 
competency guidelines for program graduates that include information literacy and related skills.

\section{Lecture Courses}

Many courses in the life sciences utilize a lecture-based format of instruction to teach the theory. These lecture courses often utilize multiple lecture exams and a final exam to assess student learning, although some will integrate additional quizzes, papers, and projects. Recently, there has been a trend toward incorporating more active learning modalities, including problem-based learning, case studies, and computer-based activities, into the science curriculum (Handelsman et al., 2004).

\section{Laboratory Sections}

Courses in the life sciences typically have laboratory sections associated with them to provide students with hands-on experiences to learn the concepts covered in the lecture portion of the course. It is the ideal setting for students to develop the habits of mind and practices of a scientist, especially the ability to identify the characteristics of science and think scientifically (Leonard, 1997). These laboratory sections are held once or twice weekly for several hours to allow the time to complete the laboratory-based explorations of the concepts. These laboratory sections can be more accessible in terms of the availability of time to integrate additional activities. Moreover, these courses often require students to complete laboratory reports using the IMRAD format (Introduction, Methods, Results, and Discussion). Students are typically required to consult and cite authoritative sources in the Introduction and Discussion sections, and this provides a meaningful opportunity for integrating information literacy concepts and skills and to produce work that can be directly assessed to measure their learning.

\section{Lower-Division Courses}

In the curriculum for life sciences disciplines, many lower-division courses serve as prerequisites for upper-division courses in those majors. Consequently, these lower-division courses offer an opportunity to introduce foundational skills that will be beneficial and necessary as students 
complete the subsequent, more advanced courses in their majors. They can also serve as support courses for majors in other disciplines, such as biomedical engineering or psychology. In addition, many institutions require all students regardless of major to take a science course as part of their general education requirements. Life sciences courses, especially introductory biology courses, are quite popular as an option to fulfill the science general education requirement. In fact, some institutions offer a non-major biology course designed to meet the needs and demands of this population. This is an important consideration to remember when planning information literacy instruction for these courses, as not all students will be equally facile and engaged with the concepts they are learning.

\section{Upper-Division Courses}

Courses at the upper-division level build upon the content introduced in lower-division courses, incorporating more advanced concepts and topics. Upper-division courses are very specific to the major within the discipline, and often contain more content than there is time to fully integrate, especially as scientific knowledge continues to grow at a rapid pace (Leonard, 1997). Consequently, these courses provide fewer opportunities to incorporate additional learning objectives such as information literacy instruction. Despite this constraint, they provide excellent opportunities for students to practice the skills they have acquired in lower-division courses, helping them move toward proficiency. In many cases, students can be asked to incorporate what they have learned previously, with moderate extensions of learning, without the need to devote large blocks of class time for additional instruction. Such courses also lend themselves well to an embedded model of librarian involvement.

\section{Required vs. Elective}

The curriculum in each major in the life sciences contains a number of required courses that students must complete in order to earn their degrees. These will vary among the majors, but there is likely to be some overlap. The elective courses allow students to shape their majors to meet their specific needs and interests. When planning information literacy instruction in these majors, it is best to target the required courses, as this will reach the greatest number of 
students in the degree program. The elective courses are best-suited for providing additional opportunities for students to practice the information literacy skills they have learned in the required courses, which will increase the likelihood of achieving proficiency toward the end of the degree program.

\section{Characteristics of Students in the Life Sciences}

Most students taking life sciences courses will be majors in one of the life sciences disciplines previously mentioned. Similar to other disciplines, students in these programs have a variety of ambitions for the future including further graduate-level study, professional programs, and immediate employment in their chosen fields and industries. Students pursuing further study may be seeking advanced degrees to pursue careers as bench or field scientists. Others may be seeking opportunities to teach, either in the K-12 educational system or in higher education. Those pursuing professional programs typically go into medical, dental, and veterinary doctoral programs that are highly selective and competitive. A large number of students go directly into the workforce, especially those in the agricultural and environmental sciences programs.

Students in life sciences courses, particularly those at the lower-division level, may also be nonmajors completing requirements for general education or supported degree programs (e.g., biomedical engineering, psychology). Typically, these students have had less exposure to the discipline, and they may not be as invested as students in the major. This aspect of students in life sciences courses is important to mention, as the design and the delivery of the instruction may need to be adapted to meet the situational needs of all students in the course.

\section{Collaborating with Instructors}

In order to be successful in integrating information literacy, librarians must collaborate with instructors. Instructors are often eager to find ways to familiarize students with the scholarly literature and to get them to use more appropriate and relevant sources in their assignments. Despite this eagerness, the demands on instructional faculty, particularly at research-intensive institutions, sometimes make it difficult for them to give their full attention to information 
literacy. As mentioned before, there is often more content than time for a course, leaving limited options for additional content or instruction. This should not be a source of discouragement, rather something to consider in negotiating with instructors to incorporate information literacy instruction and activities into their courses.

At research-intensive institutions, graduate teaching assistants can be willing and reliable partners in integrating information literacy instruction and activities. They often teach the laboratory sections of courses, where more time may be available to add content or instruction. In addition, these graduate assistants often are interested in learning more about information literacy themselves, as they need advanced skills to achieve their own educational aims. Moreover, these individuals are likely to be the instructional faculty of the future, so involving them in collaborations to advance information literacy skills and abilities in students now will establish a practice of working with librarians that they will carry with them into their future careers.

\section{Key Opportunities for integrating Information Literacy}

The life sciences curriculum offers ample opportunities to integrate information literacy into existing course activities. Some examples of this include laboratory reports, research papers, capstone projects, and undergraduate research experiences.

\section{Laboratory Reports}

Laboratory courses are ubiquitous in the life sciences, as many of the topics require hands-on experience with and investigation of the concepts. The laboratory report is a popular artifact of student learning in these courses, and most instructors require students to consult outside information sources as part of this process. As such, this provides a relevant and meaningful opportunity for information literacy. In fact, the laboratory report can be used to integrate several of the frames from the 2016 Framework for Information Literacy in Higher Education (ACRL Board, 2016), which will be discussed later in this article. 


\section{Research Papers}

Another popular artifact of student learning in life sciences is the research or term paper. These will often be included as part of lecture courses in addition to the exams. At some institutions select life sciences courses may be writing-intensive, allowing students to fulfill both the curricular requirement and the institution's writing requirement. For the most part, instructors will expect students to use the scholarly, peer-review literature as sources in these papers, and this provides an excellent opportunity to introduce and reinforce how to discern different types of literature sources and the concept of peer review.

\section{Capstone Projects}

The capstone course or "senior" seminar is common in the life sciences curriculum, and it provides another great opportunity for engagement. These courses are intended to "bring everything together" and allow students to demonstrate their proficiency with synthesizing concepts essential to the discipline of the major. Written reports, oral presentations, posters, and portfolios are all common products of student learning in capstone courses. Consequently, this is an excellent opportunity for students to demonstrate proficiency in information literacy and its related skills, knowledge, and abilities. Despite this, in reality, it is common for instructors to reach out to librarians to ameliorate poor information research skills in students who are expected to perform at a much higher level of competency but have not been given adequate opportunities for learning and practice.

\section{Undergraduate Research Experiences}

Undergraduate Research Experiences have become more popular in recent decades, and these provide an excellent opportunity to work directly with students to support their research endeavors. According to F. Farmer, Director of Research Development, Arizona State University, funding agencies such as the National Science Foundation and the National Institutes of Health are showing an increasing interest in including undergraduate students in sponsored research projects (F. Farmer, personal communication, December 27, 2016). These experiences often include a culminating project, which is often presented orally or in written form. Some 
institutions have self-published undergraduate research journals in which students submit their scholarship for peer-review and publication. Librarians are important partners here, as they can provide group instruction and individualized assistance to student participants with their projects and assist them with the dissemination of their results through posters, presentations, and papers.

\section{Information Literacy Competencies}

The information literacy skill set desired in students is another important aspect to consider when designing information literacy for life sciences. Both the Information Literacy Standards for Science and Engineering/Technology (ALA/ACRL/STS Task Force on Information Literacy for Science and Technology, 2006) and the Framework for Information Literacy for Higher Education (ACRL Board, 2016) can be used to guide the development of information literacy competencies for students in the life sciences. Neither of these documents is designed to be prescriptive, rather they should be used to identify and develop the criteria for information literacy competence in life sciences students. Instructional faculty should be included in these discussions, as they can provide insight and specific details about the information literacy skills they expect of students upon completion of their respective degree programs.

\section{Information Literacy Standards for Science and Engineering/Technology}

The Information Literacy Standards for Science and Engineering/Technology derive from the now-superseded Information Literacy Competency Standards for Higher Education (ACRL, 2000) and specifically address the specialized characteristics of the science, engineering, and technology disciplines. Each of the standards includes performance indicators and associated objectives to describe the skills and abilities desired of information literate students in sciencerelated disciplines. Although the professional community has moved toward a threshold concepts-based approach for information literacy competency, it is helpful to use elements of these still-adopted standards to guide the planning and design of information literacy in the life sciences, especially as students engage more with the data and visualized information that 
prevails in the life sciences disciplines. It will continue to be important for students in the life sciences to be able to

- $\quad$ specify the type and amount of information needed;

- gather the appropriate information in a productive manner;

- critically evaluate information and sources and modify the information seeking strategy as needed;

- use information in an ethical and legal manner; and

- engage in lifelong learning to stay up-to-date with emerging trends and developments in the field (ALA/ACRL/STS Task Force on Information Literacy for Science and Technology, 2006).

Critical evaluation of information and its sources is also important, especially considering the recent onslaught of 'fake news' that has quickly dominated the social media landscape. The last outcome listed is likely the most important, as professionals in the life sciences (e.g., doctors, scientists) are expected to stay continuously engaged with information relevant to their professions throughout their careers.

\section{Framework for Information Literacy for Higher Education}

The ACRL 2016 Framework for Information Literacy for Higher Education provides a new and flexible way in which to employ information literacy in higher education. The Framework emphasizes a "dynamic and often uncertain information ecosystem," the role that students play in "creating new knowledge," and the importance of "metacognition, or critical selfreflection." It focuses on threshold concepts, which represent the idea that once a student has grasped the knowledge fully they are transformed; the knowledge cannot be lost or undone; and they will not retreat to their previous, limited state of understanding (Meyer \& Land, 2006). The ultimate goal is a shift forward in their understanding of a complex idea.

One of the most important aspects of the Framework for Information Literacy for Higher Education and one that is fundamentally different from the previously sanctioned Information 
Literacy Competency Standards for Higher Education lies in how it should be employed. The Framework is not intended to be a directive, rather it allows stakeholders to determine how to best use it based on their own needs at their respective institutions (ACRL Board, 2016).

The Framework for Information Literacy in Higher Education can be viewed through the lens of the life sciences, and the following provides a brief summary of some of the important aspects of each frame.

\section{Authority Is Constructed and Contextual}

Scientists and researchers who publish in scholarly, peer-reviewed journals are the longstanding, recognized authority in the life sciences. While there are always exceptions, students should recognize this standard of authority within the discipline and maintain a healthy skepticism about using sources in which authority cannot be verified. Information in the life sciences often requires a high level of authority. For instance, medical information should come from individuals who have been properly trained, credentialed, and vetted.

\section{Information Creation as a Process}

In the sciences, information creation is grounded in the scientific method, which includes "(a) systematic observation, measurement, and experimentation; (b) induction and the formulation of hypotheses; (c) the making of deductions from the hypotheses; (d) the experimental testing of the deductions; and (if necessary) (e) the modification of the hypotheses" (Scientific method, 2016). The predominant form for delivery of information in the life sciences is the scholarly, peer-reviewed article. Despite both of these long-standing processes, new models of information creation and publication are emerging as a result of advances in technology (e.g., open peer review).

\section{Information Has Value}

The high cost of journals in the life sciences disciplines is one of the most prevalent examples of this concept. Related to this is the notion of free access to taxpayer-funded research, which has 
been available at an increasing rate for nearly a decade. In addition, students should understand the importance of giving credit where due and the value of their own contributions to the information landscape. This latter aspect is critical for underrepresented minorities in the life sciences, who may experience challenges to professional advancement disproportionate to other groups of students (F. Farmer, personal communication, December 27, 2016).

\section{Research as Inquiry}

The purpose of scientific research is to investigate unanswered questions and gaps in the existing knowledge within the field of study. One of the fundamental roles of scientific study is to generate further questions for inquiry and investigation. In the sciences, the scholarly literature is the forum for the debate and discussion of knowledge within the scientific community. Students should recognize the importance of using appropriate sources to draw conclusions and synthesize ideas in the life sciences.

\section{Scholarship as Conversation}

Scientists have traditionally communicated results of research and debated issues through the scholarly, peer-reviewed literature. This long-standing practice is evolving as new and social media gain traction as a means of communicating scientific information. Students play an important part in this construct as emerging professionals, and they should begin to view themselves and engage as participants in this conversation in preparation for their future professional work.

\section{Searching as Strategic Exploration}

Students must know the important sources of information in the life sciences and then search them effectively to locate the needed information, matching their information needs with the best approaches and tools. As such, it is important to utilize the most effective tool, to use an appropriate search strategy, and to select a relevant information source. As with other disciplines this process is iterative and requires a high level of persistence and curiosity. 
Students in the life sciences are likely to be more facile in this way, as these disciplines often attract those drawn to inquiry.

\section{Designing with the Objective-Activity-Assessment Approach}

This next section addresses a systematic, assessment-based approach for information literacy in the life sciences. The topic of assessment-based approaches for student learning is broad and deep and includes much more than can be covered in this chapter alone. What follows will 'scratch the surface' of this topic, highlighting the important aspects and providing practical guidance.

The Objective-Activity-Assessment Approach (Figure 1) includes the following steps: develop learning objectives, design learning activities, and assess student learning (note: delivery of instruction is part of the sequence but will not be addressed in this chapter). Assessment is defined as "the ongoing process of

- establishing clear, measurable expected outcomes of student learning;

- ensuring that students have sufficient opportunities to achieve those outcomes;

- systematically gathering, analyzing, and interpreting evidence to determine how well student learning matches our expectations; and

- using the resulting information to understand and improve student learning" (Suskie, 2009, p. 4).

The Teaching Tripod Approach employs a similar, straightforward method for designing information literacy instruction that matches well with the definition above. It incorporates expected learning outcomes, activities, and assessment into the instructional design process by examining what we expect students to learn, how they will learn it, and how we know they have learned, respectively (Kaplowitz, 2014).

[INSERT FIGURE III.1 HERE] 


\section{Developing Learning Objectives}

Learning objectives (also known as learning outcomes) are essential for effective learning. They help to articulate what students should be able to do as a result of the instruction, and consequently aid in designing more effective instruction planning, activities, and assessments (Gronlund, 2000). When developing learning objectives, carefully consider what students should learn and be able to accomplish from the instruction. The revised Bloom's Taxonomy (Anderson et al., 2001) is very helpful for writing action-based learning objectives and identifying the appropriate cognitive level (Figure 2).

[INSERT FIGURE III.2 HERE]

A basic formula for creating a learning objective is:

Students will be able to + ACTION (verb) + SKILL/KNOWLEDGE/ABILITY

For instance, in an environmental sciences course, students should be familiar with examples of grey literature relevant to that subject area (e.g., government documents such as U.S. Forest Service General Technical Reports).

Learning Objective $=$ Students will be able to name two relevant examples of grey literature relevant to the environmental sciences

This learning objective would fall in Level One (Remember).

Moving to the next level (Understand), students should understand how grey literature sources are important to the field of environmental sciences.

Learning Objective $=$ Students will be able to explain the role of grey literature sources in the environmental sciences

Writing learning objectives can be challenging, especially at first. With practice, however, it becomes easier, and there are a number of books, articles, and web-based resources available to provide guidance. 
Information literacy learning objectives should be aligned with those at the course, program, and institution levels (Figure 3). The learning objectives created for the information literacy component of the course should be connected to what students are expected to learn as part of the course itself. Collectively, these objectives should contribute to the achievement of the program-level, and, ultimately, the institution-level objectives. Such alignment ensures that the information literacy instruction is value-added and intentional ( $\mathrm{O}^{\prime} \mathrm{Clair}$, in press).

[INSERT FIGURE III.3 HERE]

\section{Designing Learning Activities}

Once the learning objectives have been established, the learning activities can be designed and planned to ensure that the concepts are reaching students and that the students are given adequate opportunities to learn them. The learning activities should always assist students in achieving the expected learning objectives. If the learning objectives change over time, the learning activities will need to be revised to reflect the new updated objectives, and vice versa.

Designing active learning experiences gives students the greatest chances for successful learning, because they will be engaged in the learning process and will develop a deeper understanding of the material that will be retained longer (Leonard, 1997). Active and problembased learning approaches are particularly well-suited for the life sciences, as students are familiar with employing concepts in the laboratory, and the curriculum provides a wealth of real-world examples with which to work. For example, many instructors in the life sciences want their students to be able to locate and read the scholarly literature in their respective fields. A problem-based learning experience in which a research team (in this case, a group of students) must find and retrieve several articles on habitat utilization by migratory songbirds during stopover (in this case, the research topic) in order to identify existing knowledge and gaps (in this case, synthesize the information) would work well here. 
One of the most important aspects of designing learning activities involves ensuring that students can articulate the purpose of the activity, the tasks associated with the activities, and the measures used to determine successful completion. Transparent assignment design helps to create learning opportunities that are student-centered, making it easier for students to grasp the concepts they are expected to learn and why they are important. The University of Nevada, Las Vegas, has developed a freely available checklist for designing transparent assignments for use in developing learning activities and assignments for information literacy instruction (Winkelmes, 2016).

\section{Assessing Student Learning}

Assessment has gained considerable popularity in recent decades, as institutions strive to measure their value and demonstrate student learning. Libraries should engage in meaningful assessment to demonstrate their value to the institution and to measure their contributions to student learning, especially in the area of information literacy (Oakleaf, 2011). The process of assessing student learning can be complex and challenging, yet there are a number of straightforward approaches that can be incorporated using formative and summative assessment methods.

Formative assessment measures student learning along the way, providing opportunities to make adjustments to the teaching and learning to ensure students are progressing as expected. This is beneficial to the student, who can use the formative assessment activity to self-regulate their understanding of the concepts, as well as to the instructor, who can identify whether students are grasping the concepts being taught. Classroom Assessment Techniques (CATS) are widely used as a type of formative assessment (Angelo \& Cross, 1993) and can be used in a variety of ways and at multiple points during instruction. For instance, using the prior example about grey literature sources, an online poll could be incorporated mid-way through the instruction session to ensure that students are able to identify grey literature sources of information, and then adjust accordingly if they fall short of the expected results. Formative assessment is beneficial to students because it provides early identification of and intervention 
for students who are struggling with the concepts, as well as multiple chances to learn and move toward success in achieving the learning objectives. In addition, it helps students be more successful in adequately completing the culminating course activities such as the summative assessment examples of term papers and final exams.

Summative assessment measures student learning upon completion of the learning activities or the course, and it is usually focused on the intended learning outcomes (Suskie, 2009). In life sciences courses, this generally comes in the form of a culminating assignment, such as a term paper or presentation, or a portfolio as part of a capstone course. Rubrics are often used to assess student learning through these products, as they provide detailed characteristics of performance that are scaled and can be applied subjectively (Booth, 2011). In information literacy instruction, many of the same methodologies used in formative assessment can be applied (Booth, 2011). Self-reflection, as one example of summative assessment, can be effective, especially if it is employed holistically in an artifact such as a Researcher's Memo, in which a student discusses and evaluates their own learning throughout the entire experience. While summative assessment occurs at the end of the learning experience, it should not be confused with evaluation. The emphasis should be on how well the student has learned the content, not how they rated the experience or its delivery.

Assessment measures generally fall into two categories: direct and indirect (Table 1). "Direct evidence of student learning is tangible, visible, self-explanatory, and compelling evidence of exactly what students have or have not learned" (Suskie, 2009, p. 20). Examples of direct evidence include research papers and projects, capstone experiences, and students' selfreflection on their learning. "Indirect evidence consists of proxy signs that students are probably learning" (Suskie, 2009, p. 20). Course grades, graduation rates, and student perceptions are common types of indirect evidence of student learning. Direct measures should be used as often as possible because they provide actual evidence of learning from the students' work and experiences (e.g., from self-reflection). 


\section{Programmatic Approaches for Information Literacy in the Life Sciences}

One of the first steps toward developing a more programmatic approach to information literacy instruction involves taking an inventory of established and potential opportunities for instruction. Librarians need to know the aforementioned characteristics of the life sciences curricula in order to determine the following questions:

- In which courses do students currently receive information literacy instruction?

- Where do those courses fall in the curriculum?

- What courses are students required to complete for the major?

- When do students take those required courses?

- Are there opportunities to integrate additional instruction?

- Are there concentrated areas of information literacy instruction (or gaps) in the curriculum?

The next step involves determining the sequence of courses in which students will receive information literacy instruction. Librarians should work closely with academic departments in this activity to gain an understanding of how students typically move through the coursework in the major. In this process, determine the best possible courses in which to include information literacy instruction or activities. Instructors and departments need to agree to allocate time in their courses and programs to integrate information literacy, and this often must be negotiated with flexible and creative solutions.

The final step ensures that students will have sufficient opportunities to achieve the intended learning objectives. This involves identifying the courses in which the learning objectives will be addressed; determining where and when the corresponding concepts and skills will be introduced and practiced; and selecting the courses in which students are expected to demonstrate proficiency and achievement of the desired learning objectives.

\section{Recommendations and Practical Advice}


Many librarians charged with information literacy instruction in the life sciences serve academic units with large numbers of students, and this is especially the case at research-intensive institutions. Regardless of the institution's size, creating instruction that is scalable will help to optimize the instructional efforts to achieve the widest reach. While not all information literacy efforts can be scaled easily, it is important to consider how to design and deliver the instruction to reach the greatest number of students without losing its effectiveness. Piloting a new instructional activity on a smaller scale to start can provide the insight needed to adjust it to reach a wider number of students. In many cases, the materials and approaches will already be developed, and these can be adapted to fit a larger group or applied in an additional discipline.

Planning and designing instruction that can be adapted to withstand changes in personnel, curriculum, and priorities will help to ensure sustainability of your instructional endeavors. Many instructors teach a variety of courses from term-to-term and having multiple sections of a course is a common occurrence, especially for foundational courses in the life sciences. Thus, collaboration with several different instructors may be needed in order to integrate the instruction that has been designed. One of the benefits of using the Objective-ActivityAssessment Approach outlined above is that it helps to articulate and demonstrate the value of information literacy in the curriculum, which will be essential over time as priorities of both the department and the library evolve and change.

It is important to be intentional and strategic when planning information literacy instruction in the life sciences. The Information Literacy Instruction Planning Worksheet can assist librarians with planning information literacy instruction in a more intentional and strategic manner ( $\mathrm{O}^{\prime} \mathrm{Clair}$, in press). The process of reflecting on both the successes and failures with information literacy instruction will also help. The process of planning in an intentional and strategic way can be difficult, so it is important not to let 'perfect' get in the way of 'good.' Sometimes 'good enough' really is good enough and the most practical. 
Planning, designing, and delivering information literacy instruction is a time-intensive endeavor. Frequently, the strategies and successes of our colleagues in their instructional efforts are shared with little mention of the painstaking and lengthy amount of work that went into the process. While it is beneficial to focus on success, it is important to understand that these endeavors often do not pay off immediately and certainly not without significant time and effort. Set realistic goals and expectations for all stakeholders. Celebrate the successes and learn from what did not go as expected. Sometimes we gain the most insight from those things that did not turn out the way we intended. Give this process the time it needs to develop and mature in the way that will be the best for all involved.

Successful integration of information literacy into the life sciences curriculum relies heavily on collaboration and partnership with the academic department and its instructors. In fact, because of the compressed curriculum in the life sciences disciplines and the subjective nature of the learning activities, buy-in from the department and the instructors is required in order to best match the instructional intervention with the need and to negotiate for valuable class time to deliver the instruction. Librarians should be flexible and creative in identifying the best strategy for integrating information literacy activities and instruction into both the specific course and the curriculum. One size fits all rarely works in reality, and librarians should be encouraged and empowered to determine what is best for their situations and then design and deliver accordingly.

\section{Conclusion}

Designing information for the life sciences is an exciting and engaging endeavor, and this chapter has examined this process by providing an overview of the important aspects to consider. Whether it is a one-shot session or a fully integrated information literacy program, the design, development, and delivery of the instruction requires librarians to be familiar with the concepts presented here. With this arsenal of information, librarians can begin to establish the situation-specific teaching and learning practices that will provide a satisfying and meaningful educational experience for all involved. 


\section{Acknowledgements}

This chapter is dedicated in loving memory of Dr. Cari Lynn Finney Ouderkirk, who believed in me and taught me to believe in myself. Special thanks to Faye Farmer and Catherine Hillman for their thoughtful review of and detailed guidance on this chapter.

\section{Recommended Resources}

Booth, C. (2011). Reflective teaching, effective learning: Instructional literacy for library educators. Chicago: American Library Association.

Bowles-Terry, M., \& Kvenild, C. (2015). Classroom assessment techniques for librarians. Chicago: Association of College and Research Libraries.

Bravender, P., McClure, H., \& Schaub, G. (Eds.). (2015). Teaching information literacy threshold concepts: Lesson plans for librarians. Chicago: Association of College and Research Libraries.

Broussard, M. S., Hickoff-Cresko, R., \& Oberlin, J. U. (2012). Snapshots of reality: A practical guide to formative assessment in library instruction. Chicago: Association of College and Research Libraries.

Hopkins, E. (2012). Life and health sciences. In K. O’Clair \& J. Davidson (Eds.), The busy librarian's guide to information literacy in science and engineering (pp. 35-46). Chicago: Association of College and Research Libraries.

Kaplowitz, J. (2014). Designing information literacy instruction: The teaching tripod approach. Lanham, MD: Rowman \& Littlefield. 
Suskie, L. (2009). Assessing student learning (2nd ed.). San Francisco: John Wiley \& Sons.

\section{References}

ALA/ACRL/STS Task Force on Information Literacy for Science and Technology. (2006). Information literacy standards for science and engineering/technology. Retrieved December 12, 2016, from http://www.ala.org/acrl/standards/infolitscitech

Anderson, L. W., Krathwohl, D. R., Airasian, P. W., Cruikshank, K. A., Mayer, R.E., Pintrich, P. R., et al. (Eds.). (2001). A taxonomy for learning, teaching, and assessing: A revision of Bloom's taxonomy of educational objectives (Abridged ed.). New York: Addison Wesley Longman, Inc.

Angelo, T. A., \& Cross, K. P. (1993). Classroom assessment techniques: A handbook for college teachers. San Francisco: Jossey-Bass.

Association of College and Research Libraries [ACRL]. (2000). Information literacy competency standards for higher education. Retrieved December 12, 2016, from http://www.ala.org/acrl/sites/ala.org.acrl/files/content/standards/standards.pdf

Association of College and Research Libraries [ACRL] Board. (2016). Framework for information literacy for higher education. Retrieved December 12, 2016, from http://www.ala.org/acrl/standards/ilframework

Booth, C. (2011). Reflective teaching, effective learning: Instructional literacy for library educators. Chicago: American Library Association.

Fabbi, J. (2014, October). Creating context for information literacy: Best practices for learning and assessment. Unpublished, WASC Senior College and University Commission, retreat 
on core competencies: critical thinking and information literacy, 16-17 October 2014, Oakland, CA.

Gronlund, N.E. (2000). How to write and use instructional objectives (6th ed.). Upper Saddle River, NJ: Prentice-Hall, Inc.

Handelsman, J., Ebert-May, D., Beichner, R., Bruns, P., Chang, A., DeHaan, R., et al. (2004). Scientific teaching. Science, 304(5670), 521-522.

Kaplowitz, J. (2014). Designing information literacy instruction: The teaching tripod approach. Lanham, MD: Rowman \& Littlefield.

Leonard, W. H. (1997). How do college students learn science? In E. Siebert, M. Caprio, \& C. Lyda (Eds.), Methods of effective teaching and course management for university and college science teachers (pp. 5-20). Dubuque: Kendall/Hunt.

Meyer, J. H. F., \& Land, R. (2006). Threshold concepts and troublesome knowledge: An introduction. In J. H. F. Meyer \& R. Land (Eds.), Overcoming barriers to student understanding: Threshold concepts and troublesome knowledge (pp. 3-18). New York: Routledge.

Oakleaf, M. (2011). Are they learning? Are we? Learning and the academic library. Library Quarterly, 81(1), 61-82.

O'Clair, K. (in press). Intentionally planning information literacy instruction. In B. West, K. Hoffman, \& M. Costello (Eds.), Creative instructional design: Practical application for libraries. Chicago: Association of College and Research Libraries. 
Scientific method. (2016). In Oxford English dictionary. Retrieved December 12, 2016, from http://www.oed.com/

Suskie, L. (2009). Assessing student learning (2nd ed.). San Francisco: John Wiley \& Sons.

Vanderbilt University Center for Teaching. (2001). Bloom's taxonomy (Licensed under Creative Commons 2.0 [no changes made]). Retrieved September 6, 2016, from https://www.flickr.com/photos/vandycft/29428436431

Winkelmes, M. (2016). Self-guided draft checklist for designing a transparent assignment. In Transparency in learning and teaching project (TILT): Transparent methods. Available from https://www.unlv.edu/provost/transparency 